Catura, Santa Maria, v. 37 n. 3 esp. 2015, p. 16-2

Revista do Centro de Ciências Naturais e Exatas - UFSM

ISSN impressa: 0100-8307 ISSN on-line: 2179-460X

\title{
Relationship between Investors Sentiment Index with First and Second Market Indexes in Tehran Stock Exchange (TSE)
}

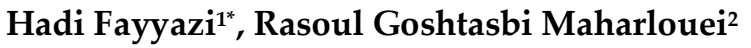

${ }^{1}$ M. A. of Finance, Science and Research Branch, Islamic Azad University, Iran.

${ }^{2}$ M. A. of Finance and lecturer, department of Accounting and management, Islamic Azad University , Beyza Branch , Iran

\begin{abstract}
The process of being affected of the investors in decision making from their sentiment has been considered in many recent researches in the field of the financial assets pricing. Some authors suggest that shifts in investor sentiment may in some instances bette rexplain shortterm movement in asset prices than any other set of fundamental factors. The present study tries to investigate the relation between the investors sentiment index and First and Second Market Indexes in Tehran Stock Exchange Market. This paper, an index was used in order to measure the available data on sentiment of the investors in facing the risks in a 142 -month period $(2001$ - 2014) in Tehran Stock Exchange. The used index can reveal and present the situation of the Iranian capital Market in terms of the Investors Sentiments. The results obtained from the present study reveal a positive and significant relation between the investors' sentiment Index of the Tehran Exchange First and Second Market Indexes; and also by using from Granger Causality Test, it was revealed that there is a mutual causality relation between the investors' sentiment Indexes of the TEFMIX and TESMIX.
\end{abstract}

Keywords: Behavioral Finance, Equity Market Sentiment Index, Tehran Stock Exchange 


\section{Introduction}

he Traditional financial theory suggests $\mathrm{T}$ that stock price shows basic and fundamental value of stocks which reflects value of future cash trends. Based on efficient market hypothesis, investors show rational behavior, i.e. they process all accessible and available information and are after maximizing expected favorability. Accordingly, stock price's changes are related to the systematic changes in fundamental values of the firm and sentimental behavior of investor has no effect on return. Even if some investors create shock in supply and demand with their sentimental transactions, other rational arbitragers will neutralize impact of these shocks. Therefore, stock's price will remain at a fundamental level [11]. But the evidences indicate that investors do not use quantitative methods for the determination of stock value. Judgments are based on subjective imaginations, unscientific data and mental and sentimental conditions at stock market. Sentimental variables, which are formed based on cognitive restrictions, will study mental conditions of stock market activists [16]. Financial behavior is one of the studies which is developed rapidly in this field and is tasked with studying decisionmaking process of investors and their reaction towards various conditions of financial markets. Moreover, financial behavior focuses more on influence of sentiments, personality, culture and judgments of investors on investment decision making. Daniel Kahneman is one of the founders of this field of financial knowledge. Behavioral finance perspective shows that some changes in price of stocks and securities do not have any basic reason and investor sentiment tendency plays a very important role in determination of prices [11]. As a matter of fact, dynamic interaction and interplay between Noise Traders and rational arbitragers form stock prices. If one stock of Noise Traders exceeded and/or one stock of rational traders reduced, its price volatility is noticeable [16]. Behavioral finance perspective represents two basic assumptions: The first assumption is this that investors make decision under the influence of their sentiment. Here, sentiment, in the form of belief, is defined to the future cash trends and investment risks, so that this belief is not created by the accessible truths. The second assumption is this that arbitrage is riskiest and costliest for sentimental investors. Therefore, rational investors or arbitragers are not more dynamic in terms of returning prices to the basic price. Modern behavioral finance believes that there are restrictions for arbitrage.

\section{Literature Review}

In this study, investors' sentiment is evaluated and its influence is measured on stock return. Investors' sentiment can be defined as "Investors' Tendency to Speculation". From this aspect, investors' sentiment is led to the creation of relative demand for speculative and gambling investments and this affair will have crosssectional impacts on stock price. But a question is posed here: "Which factors will lead one stock to be vulnerable to the investors' tendency to gambling? Subjectivity of pricing and evaluating stocks may be considered as the most important reason of the said Issuae [1].

Another definition that can be explained for investors' sentiment include as follows: "Margin of Degree of Optimism and Pessimism of Shareholders to a Stock" [11]. The measurement method of investors' sentiment can be classified into three groups: The first group of investors' sentiment index is based on survey methods which measures market sentiments directly. Of this group, it can be referred to Michigan Consumer Sentiment Index (MCSI). The indirect methods are in opposite direction of direct methods which are taken advantage of financial data in order to measure investors' sentiment. Of direct methods, it can be referred to buy-sell imbalance, Barron's Confidence Index, Equity Market Sentiment Index. The third group of measurement methods is related to the combined methods, the most important of which can be referred to the combined index as presented by Baker and Wurgler [2, 11]. Chen and et al [4] showed that sentiments created by social media (such as official websites and dailies) have direct relationship with the current and future stock returns. Influence of media is mainly stronger for the firms which their stocks 
are kept by the retail investors. Wu and et al [21] attributed and correlated influence of weekday and stock return with investors' sentiment for the first time. Empirical estimates indicate that role of influence of weekday in return is similar to the role of investors' sentiment on return and belongs to the stocks with high subjective evaluation. For example, the stocks with low market value are more affected by sentiment at the time when effect of weekday is stronger. Also, in this study, high relationship was discovered between sentiment and return. Kim and Ha [11] studied effect of investors' sentiment on stock price. For this reason, they created four sorted portfolio quintiles based on size, book to market value, institutional ownership and price and concluded that investors' sentiment affect stock price of small-size Korean firms, low stock price and low ratio of book to market value coupled with low institutional ownership systematically. Also, they concluded that adding investors' sentiment index to the pricing model of capital assets improves performance of model and also clarifies effects of size, value and momentum better. Ling and et al. [14] found out positive relationship between investors' sentiment and subsequent three-month returns at two real private and public markets. They also concluded that investors' sentiment play more continual role in deviating from fundamental values, creating obstacles ahead of taking advantage of opportunity by informed arbitragers at private markets (due to lack of liquidity, information asymmetry and restriction in disclosure of price) than public markets. Hengelbrock and Et.al [9] used two investors' sentiment indexes of AAII and Sentix from U.S. and Germany respectively. They concluded that investors' sentiment index is related with the future returns in U.S. negatively and positively in Germany. Also, they found out positive effect of proclamation day in Germany. In addition, negative impact of publishing day of investors' sentiment was confirmed for U.S. market during 1987 - 1994.But effect of publishing day is insignificant in other periods, i.e. return index shows reaction to the publication of investors' sentiment index. Baker and Wurgler [2] studied the way of impact of investors' sentiment on the stock cross-sectional return. According to their results, they found out that when investors' firstperiod sentiment index is in low level, stock returns of small, newly-established, volatile, nonprofit- yielding firms will face higher financial crises and vice versa. This subject indicates that such stocks are priced lower than truth relatively in declining periods of investors' sentiment.

In other study, Kumar and Lee [12] studied models related to the transaction of Noise Traders. Their findings indicated that retail systematic transactions clarify return changes of the stocks which are more paid attention by retail transactions (including stocks of small firms, low price and ratio of low institutional ownership) and this issue is outshined more with regard to the stocks which enjoy higher arbitrage cost. According to their conclusion, they found out that tendencies and inclination of investors' sentiment play a key role in creation of return. Li [13] studied the measurement of sentimental tendency risk of annual reports and concluded that the risk can predict future returns. The firms which have major growth in sentimental tendency risk, they will have negative returns than other firms during 12 month period after publishing annual report. Jones and Bandopadhyaya [10] presented an index entitled "Equity Market Sentiment Index (EMSI)" using model proposed by Persaud [18] which shows acceptance of inherent risk in a time interval using data from capital market sentiment. They concluded that EMSI has highly correlated with the stock return index and price changes at the market are concerned with the investors' sentiment. The EMSI is constructed using stock market price data for firms listed in the Massachusetts Bloomberg Index (MBI).It is found that changes in the EMSI are closely related to news items regarding key firms in Massachusetts as well as to news reports on the condition of the Massachusetts economy as a whole. It is also found that changes in the MBI are related to the EMSI. In fact, the results indicate that lagged values of the EMSI better explain changes in the MBI than do past changes in the MBI itself (ie MBI's own price momentum). In his study, Brown [3] found out that sentiment of Noise Traders is associated with the price volatilities positively. In the field of arbitrage, Shleifer \& Vishny [20] explained theoretically that unstable and volatile securities will face bigger pricing mistake in a noise trading and earn higher average return. 
Nikoumaram and Saeidi [17] used the index designed by Jones \& Bandopadhyaya for the calculation of stock market sentiment at Tehran Stock Exchange (TSE) and recalled it as the most accessible and salient index in terms of accessing information at Iranian stock market. Based on investors' sentiment index at Equity Market Sentiment Index (EMSI), they embarked on studying feasibility studies of return using this index. Therefore, they concluded that possibility of prediction of market return was confirmed by the index. In the same direction, the mentioned study showed that possibility of whole market rate of return can be grasped out through investors' sentiment index using Regression Model. Also, in this study, this conclusion was approved that investors' sentiment index is the main reason of changes in cash return index and price using Granger Causality Test. In other words, explanatory ability of changes of return was approved by the investors' sentiment index. Heidarpoor, et al. [8] investigated the impact of investor sentiment on the stock returns of portfolios that were arranged by size, price, book value to market value and the rate of characteristic ownership using EMSI index. They concluded that there is a positive and significant relation between investor sentiment and the return of the stock of companies with the least size, price, book value to market value ratio, and characteristic ownership rate.

Fayyazi , et al. [6] investigated the relation between the investor sentiment index and returns in Tehran Stock Exchange. They confirmed the positive relation between the two indices and demonstrated there is causal relation between them.

\section{Research Methodology and Hypotheses}

This paper is a branch of quasiexperimental researches and also a post-events type (by the use of previous information). It is based upon real information of share market and financial statements of all listed firms at Tehran Stock Exchange Organization during March 21, 2001 up to March 20, 2013.

The present research is of applied one in terms of objective. In the same direction, the present study is of a descriptive-correlative one in terms of execution method. In this study,
Multivariate Regression Model has been used for the analysis of data and test of hypotheses using time series.

" $\mathrm{t}$ " statistics has been used in each model in order to study significance of coefficient of Independent variables. Based on the results of studying significance of whole regression according to " $F$ " statistics, it has been decided with regard to the approval or rejection of hypotheses in $95 \%$ confidence level. In linear regression model, it is necessary to study and test hypotheses of this model as follows in order to turn estimators of the Ordinary Least Squares of regression coefficient into the best estimators without linear bias:

1) Heteroskedasticity problems of variance leads to the increased variance of intercept estimated coefficients and on the other hand, it affects variance of other independent estimated variables. In this study, White Test is used to test heteroskedasticity of variance.

2) Durbin - Watson Test is used to study self-correlation of first grade of errors. If value of Durbin - Watson statistics is neared to null, it shows positive self correlation and if value of Durbin Watson statistics is neared to 4 , it shows negative self correlation.

3) Kolmogorov-Smirnov Test is used to study normality of variables and remainders. If probability value related to this test is found larger than 0.05, normality of distribution of variables and remainders can be confirmed with $95 \%$ confidence.

4) Variance Inflation Factor (VIF) is benefitted in order to study inexistence of collinear (nonexistence of significant relationship between independent variables). As an experimental rule, if value of VIF is turned larger, co-linear will be more intense.

5) Finally, Indogeneity test (unit-root test) and Augmented Dickey - Fuller unit Root Test are used to find out The stationary of variables of research.

\section{A. Research Hypotheses}

Hypotheses No. 1: There is a significant relationship between investors' sentiment index 
and First Market Index at Tehran Stock Exchange (TEFMIX).

Hypotheses No. 1.1: There is a causal relation between the investors' sentiment index and First Market Index at Tehran Stocks Exchange.

Hypotheses No. 2: There is a significant relationship between investors' sentiment index and Second Market Index at Tehran Stock Exchange (TESMIX).

Hypotheses No. 2.1: There is a causal relation between the investors' sentiment index and Second Market Index at Tehran Stocks Exchange.

\section{B. Research Model and Definition of Variables'}

The main hypothesis of this research is based on Firstly or secondly market index following regression model:

TEFMIX $_{t}\left(\right.$ TESMIX $\left._{t}\right)=C+\beta_{1}$ EMSI $_{t}+\beta_{2}$ TEFMIX

Wherein:

TEFMIX $_{t}=$ Index of the First Market in Tehran Exchange at period $t$

$\operatorname{TESMIX}_{t}=$ Index of the Second Market in Tehran Exchange at period $\mathrm{t}$

$E M S I_{t}=$ Equity Market Sentiment Index in period $\mathrm{t}$

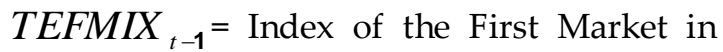
Tehran Exchange at period $t-1$

$\operatorname{TESMIX}_{t-1}=$ Index of the Second Market in Tehran Exchange at period $t-1$

To test the hypotheses based on the methodology of Nikoomaram and Saeedi [17], and Jones and Bandopadhyaya [10], the regression equations (1) will be calculated. In the regression model above, the acceptability of the hypotheses will be decided based on significance coefficients and coefficients of determination. Also, regarding the testing of secondary hypotheses using Granger Causality, it can be confirmed whether there is a causal relation between investor sentiment index and firstly and secondly market indexes in Tehran Stock Exchange or not, what the direction of this relation is, and which variable causes the other one and can explain it.

\section{Measuring investors' sentiment}

In this study, Equity Market Sentiment Index (EMSI) is used for measuring investors' sentiment in TSE. This index was suggested by Jones (2006) and was developed with the adjusted model as presented by Persaud (1999).

Therefore, investors' sentiment can be calculated using equation No. (2) as follows:

$$
\operatorname{EMSI}_{t}=\frac{\sum\left(R_{i t}-\bar{R}_{r}\right)-\left(R_{i v}-\bar{R}_{v}\right)}{\left[\sum\left(R_{i t}-\bar{R}_{r}\right)^{2}-\left(R_{i v}-\bar{R}_{v}\right)^{2}\right]^{\frac{1}{2}}} \times 100
$$

Wherein:

$R_{i t}=$ represents daily stock return of " $\mathrm{i}$ " firm in " $\mathrm{t}$ " day.

$R_{i v}=$ represents historical volatility of stocks of " $\mathrm{i}$ " firm in " $\mathrm{t}$ " day,(It should be noted that average standard deviation of stock return in preyiesw 1 fixe ${ }_{t-1}$ days was used for the calculation of historical volatility).

$\bar{R}_{r}=$ represents average grade of daily stock return

$\bar{R}_{v}=$ represents average grade of historical volatility of stock return

\section{Data Analysis and Empirical Results}

\section{A. Descriptive Statistics}

Table No. 1 presents descriptive statistics related to the researched variables at trading days.

Tab.1. Descriptive Statistics

\begin{tabular}{ccccc}
\hline Index & Obs. & Average & Max & Min \\
\hline TEFMIX & 2724 & 14979.76 & 67441.4 & 4407 \\
\hline TESMIX & 2724 & 24188.82 & 167002 & 4796 \\
\hline EMSI & 2724 & 0.646 & 82 & -79.11 \\
\hline
\end{tabular}

As it is demonstrated in the table 1, the calculated indices in terms of the number of observations, which are obtained, based on the available data and the calculated indices are acceptable in number. Also, the skewness and the kurtosis of these data, which are obtained in the form of time series, have normal distribution. Other information such as the average, 
maximum amount, minimum amount, and the number of observations is written in table 1 .
In Table 2 shows the risk appetite classes and the number of days of each class during the investigated period in Tehran Stock Exchange.

Tab.2. Risk Categorization of daily EMSI figures

\begin{tabular}{ccc}
\hline Range of EMSI & Category & $\begin{array}{c}\text { Number of } \\
\text { trading days. }\end{array}$ \\
\hline-30 and below & Highly Risk Averse & 270 \\
\hline-10 to -30 & $\begin{array}{c}\text { Moderately Risk } \\
\text { Averse }\end{array}$ & 617 \\
\hline-10 to +10 & Risk Neutral & 1226 \\
\hline+10 to +30 & $\begin{array}{c}\text { Moderately Risk } \\
\text { Seeking }\end{array}$ & 751 \\
\hline+30 and above & Highly Risk Seeking & 234 \\
\hline
\end{tabular}

stationary and lack of existence of unit root. In

\section{B. Indogeneity of Model Variables}

In the Dickey-Fuller Unit Root Test Null hypothesis in this test indicates existence of unit root or non-stationary of variables of research model and alternative hypothesis also indicate other words, if probable statistics is found less than $5 \%$, it is called as "unit-root variable", otherwise, the variable is not considered as unit root with $95 \%$ probability

Tab.3. Risk stationary of Model Variables

\begin{tabular}{ccc}
\hline Variables & t-Statistic & $\begin{array}{c}\text { P- } \\
\text { Value. }\end{array}$ \\
\hline${ }^{*}$ EMSI t & -7.09 & 0.0031 \\
\hline${ }^{*}$ TEFMIX t & -6.93 & 0.0011 \\
\hline${ }^{*}$ TEFMIX t-1 & -5.00 & 0.0020 \\
\hline${ }^{*}$ TESMIX t & -4.14 & 0.0054 \\
\hline${ }^{*}$ TESMIX t-1 & -3.81 & 0.0076 \\
\hline${ }^{*}$ Stationary at level & &
\end{tabular}

As if is observed in Table No.3, all variables are stationary at level.

\section{Hypotheses Empirical Results and Decision}

The Hypothesis NO.1 and NO.2 : the test results of this hypothesis based on the estimate of the model (1), (2) are shown in table 4 . According to table 4, in addition to the confirmation of the main hypothesis, it can also be claimed, with a $95 \%$ level of significance, that there is a positive and significant relation between the investor sentiment and the First and second market index in TSE.

Tab.4. Result of hypotheses NO.1 and NO.2 statically test

\begin{tabular}{|c|c|c|c|c|c|c|c|c|c|}
\hline \multicolumn{2}{|l|}{ Model 2 :TESMIX $t_{t}=C+\beta_{1}$ EMSI $_{t}+\beta_{2}$ TESMIX $_{t-1}+\varepsilon_{t}$} & $\begin{array}{l}\text { TESMIX } \\
\text { INDEX }\end{array}$ & \multicolumn{2}{l|}{ Model 1 TEFMIX $t_{t}=C+\beta_{1}$ EMSI $_{t}+\beta_{2}$ TEFMIX $_{t-1}+\varepsilon_{t}$} & TEFMIX \\
INDEX
\end{tabular}




\begin{tabular}{|c|c|c|c|c|c|}
\hline -------- & 1.9649 & $\begin{array}{l}\text { Durbin- } \\
\text { Watson }\end{array}$ & -------- & 1.9019 & $\begin{array}{l}\text { Durbin- } \\
\text { Watson }\end{array}$ \\
\hline 0.0000 & 264.5044 & $\begin{array}{c}\text { F } \\
\text { statistic }\end{array}$ & 0.0000 & 941.4214 & F statistic \\
\hline 0.0813 & 0.9363 & K-S Test & 0.0972 & 0.8310 & K-S Test \\
\hline 0.1709 & 4.2391 & $\begin{array}{c}\text { White } \\
\text { Test }\end{array}$ & 0.1844 & 3.0191 & $\begin{array}{c}\text { White } \\
\text { Test }\end{array}$ \\
\hline -------- & 0.3723 & $\begin{array}{c}\text { Adjuste } \\
\text { d R } \\
\text { square }\end{array}$ & -------- & 0.4093 & $\begin{array}{l}\text { Adjusted } \\
\text { R square }\end{array}$ \\
\hline -------- & 0.3913 & R square & -------- & 0.4324 & R square \\
\hline
\end{tabular}

Also, according coefficient of determination of the model, $43.2 \%$ of changes in first market index and $39.1 \%$ change in second market index are explained by the independent variables that were introduced into the model. The assumptions of the independence and the normality of the errors were tested, respectively, by Durbin-Watson test and KolmogorovSmirnov tests. The assumption of non- multicolinearity of the explanatory variables and homogeneity of variance were confirmed by VIF (Variance Inflation Factor) and White test.

\section{Results of the Secondary Hypotheses}

The results of the secondary hypotheses of the research which include the Granger Causality test between the investor sentiment and indices of first and second markets are shown in table 5.

Tab.5. Result of Granger Causality Test

\begin{tabular}{lccc}
\hline \hline Null Hypothesis: & $\begin{array}{c}\text { F- } \\
\text { Statistic }\end{array}$ Prob. \\
\hline \hline & Obs & & \\
EMSI does not Granger Cause TEFMIXt & 2724 & 76.32410 .0141 \\
TEFMIXt does not Granger Cause EMSI & & 54.0090 & 0.0373 \\
\hline \hline & & & \\
EMSI does not Granger Cause TESMIXt & 2724 & 55.16430 .0176 \\
TESMIXt does not Granger Cause EMSI & & 43.03130 .0402 \\
\hline \hline
\end{tabular}

According to this table, there is a mutual causality relation between the investor sentiment and indices of first and second markets in long term.

\section{Conclusion}

The traditional finance theory ignores the role of the investor sentiment in the price of the stocks, the achieved return, and the expected return. But, the behavioral finance view proves that investors' decisions are influenced by their sentiments and due to high risks, the rational arbitrageurs are not willing to return the prices to a fundamental level and so the incorrect pricings will not be corrected. That is why the investor sentiment has an important role in the determining the price and explanation of the return [6]. In this research the relation between the investor sentiment and indices of the First and Second markets of Tehran Stock Exchange was studied and during the investigated period, it was observed that whenever there is a drop in the indices of the first or the second market, the investor sentiment index experiences a drop as well which indicates the investors' risk-aversion and their sentiment towards the overall condition of the stock market. The same situation exists when there is a rise in the indices of the first or the second market; whenever the stocks of the companies in the first and second markets 
experiences a rise and proper rate of return or the investors' expectations of the future of these companies are high, the investors' sentiments are riled up and they become more open to risktaking and the investor sentiment index rises as well. Thus, this research has confirmed the existence of a positive and significant relation between the investor sentiment and indices of the first and second markets of Tehran Stock Exchange.

Also in a secondary hypothesis, the existence of a causal relation between the investor sentiment and indices of the first and second markets of Tehran Stocks Exchange was investigated and it was confirmed that there is a causal relation between investor sentiment and indices of the first and second markets of Tehran Stocks Exchange and that this relation is mutual. But, it must be kept in mind that rather than the market indices causing and forming the investor sentiment, it is the investor sentiment that forms the indices of the first and the second markets.

These findings are compatible with the researches of Nikoomaram and Saeedi [17] in Tehran Stock Exchange and Jones and Bandopadhyaya [10] in New York Stock Exchange.

\section{Suggestions Based on the Findings}

Considering the impact of the investor sentiment on the stock market, the investors are advised to avoid rash decisions and trade stocks with caution and proper analysis.

Based on the cultural and economic environment of Iran's stock market which as the studies demonstrated is influenced by investors' sentiments, the investors, brokers, and the audience of the stock market are advised to pay more attention to changes in sentiment in asset pricing models.

Considering the poor performance of Tehran Stock Exchange as shown by different studies, in order to enhance the performance of the market, it is suggested that the investor sentiment index be included in software packages such as Rahvard-e- Novin so that the investors can access it.

\section{References}

Baker, M., \& Wurgler, J., (2006). Investor sentiment in the stock market. Journal of Economic Perspectives, NO.21,pp 129-151.

Baker, M., \& Wurgler, J., (2006). Investor Sentiment and Cross-Section of stock returns. Journal of Finance NO.61, pp 1645-1680.

Brown, G.W., Cliff, M.T., (2005). Investor sentiment and asset valuation. Journal of Business, No.78, 405-440.

Chen, H., \& De, P., \& Yu, H., \& Hwang, B. (2011). Sentiment Revealed In Social Media and its Effect on the Stock Market, Available at www.ssrn.com

Fama, E., \& French, K. (1993). Common Risk Factors in the Returns on Stocks and Bonds. Journal of Financial Economics, vol 33, pp 356.

Fayyazi , H. , Fadaei nejad , M.E., Rezai , F., (2014) " Relationship between Investors Sentiment Index with Stock Returns in Tehran Stock Exchange (TSE) ", Asian Journal of Research in Banking and Finance vol. 4. No. 12. pp. 170-182.

Fadaei Nejad, M.E., \& Sadeghi,M. (2006). "Evaluate the usefulness of momentum and reversal strategies". journal of The Message of Management, No.17, pp 7-31.

Heidarpour F., Tari'verdi Y., Mehrabi M., (2013), “The Impact of investors' sentiment on stock returns" Journal Of Analysis of Financial Knowledge Exchange, NO.17, pp 1-13.

Hengelbrock, J., Theissen, E., \& Westheide, C. (2009) . "Market Response to Investor Sentiment" Available at www.ssrn.com

Jones, A. L., \& Bandopadhyaya, A. (2006). Measuring Investor Sentiment in Equity Markets. Journal of Asset Management, vol 7, pp 208-215.

Kim, T., \& Ha, A. (2010). Investor Sentiment and Market Anomalies. 23rd Australasian Finance and Banking Conference 2010 Paper , Australia, Available at www.ssrn.com. 
Kumar, A., \& Lee, C. (2006). Retail Investor Sentiment and Return Comovements. Journal of Finance, vol 61, issue 5, pp 2451-2486

Li, F. (2006) "Do Stock Market Investors Understand the Risk Sentiment of Corporate Annual Reports?" Available at www.ssrn.com

Ling, D., \& Naranjo, A., \& Scheik B. (2010). Investor Sentiment and Asset Pricing in Public and Private Markets. Available at www.ssrn.com

Mehrani, S., \& Nonahali, A.A. (2008) “An Investigation of Implementing Contrarian Trading Strategy in Tehran Stock Exchange (TSE)" , Journal of the Iranian Accounting and Auditing Review, Vol 15, Issue 1,No.50, pp 25-46.

Mei-Chen, L., (2010). The Effects of Investor Sentiment on Returns and Idiosyncratic Risk in the Japanese Stock Market. International Research Journal of Finance and Economics, vol 60, pp 29-43.

Nikoomaram,h., \& Saeidi, A. (2006). “Measure of Investors' Sentiment in Stock Market" journal of Biouarterly Journal of Iran's Economic Essays, Fifth year, No.9, pp 237-276.

Persaud, A. (1996). Investors' Changing Appetite for Risk,J.P. Morgan Securities Ltd., Global FX Research.

Rezaei, F. \& Nourozi, A., 2009 "Compare the predictive power of the Fama and French models, and Reward beta and the expected return on the stock". Journal of Economic Modeling Research, No.7, pp 55-76

Shleifer, A. \& Vishny, R.W., 1997 "The Limits of Arbitrage", The Journal of Finance, Vol. 52, No. 1., pp. 35-55.

Wu,Y., \& Han, L., \& Tao, K., \& Zhang, Z. (2010). Investor Sentiment and the Day-of-the-Week Effect of Cross-Sectional Return. Available at www.ssrn.com.
Fayyazi , H. , Fadaei nejad, M.E., Rezai , F., (2014) “ Relationship between Investors Sentiment Index with Free Float Index in Tehran Stock Exchange (TSE)." Adv. Environ. Biol., 8(19), 413-418, 2014 